\title{
"Hladna, kamnita in razčlovečena« - nepričakovani vplivi prenove na senzorično zaznavanje javnega prostora in vzdušje: primer Tumske ulice v poljskem mestu Plock
}

V članku avtorja proučujeta, kako spremenjena podoba ulice po prenovi vpliva na dojemanje ulice, njeno senzorično krajino in vzdušje na njej. Na primeru Tumske ulice, glavne ulice v srednje velikem poljskem mestu Plock, dokažeta, da imajo lahko tovrstne spremembe nepričakovane posledice, ki pri prebivalcih vzbujajo negativne občutke. Izsledki raziskave, ki je temeljila na mnenju članov fokusnih skupin, kažejo, da trenutno vzdušje na Tumski ulici povzroča negativne zaznave, ki se nanašajo na štiri vrste senzoričnega zaznavanja oziroma značilnosti krajine: tipne, vidne, slušne in vohalne. Negativna občutja so še močnejša pri posameznikih, ki imajo pozitivne spomine na nekdanjo ulico - na njeno stanje pred prenovo. Zaradi negativnega vzdušja na Tumski ulici in neprijetnih občutij, ki jih vzbuja, so se ulične aktivnosti prebivalcev zmanjšale na najnujnejše opravke. Navedeni izsledki kažejo, da bi morali pri oblikovanju ali preoblikovanju javnih prostorov vedno upoštevati vplive na ulično vzdušje in potrebo po ustvarjanju pozitivnih občutij.

Ključne besede: glavna ulica, vzdušje, doživljanje mesta, urbana sociologija, senzorično zaznavanje 


\section{Uvod}

Ulica kot vrsta javnega prostora je pogosta tema raziskav $s$ področja urbane sociologije ali urbane etnografije. Možni sta dve glavni metodi proučevanja in analiziranja ulic. Prva daje prednost materialnemu in urbanističnemu vidiku ter se osredotoča na to, kako materialnost ulice določa družbeno vedenje. Pri navedenem raziskovalnem pristopu je ulica del omrežja javnih mestnih prostorov (Degen, 2018; Hubbard in Lyon, 2018). Druga metoda pa proučuje družabno življenje na ulici in poudarja pomembno vlogo ulic pri zagotavljanju občutenja kraja in časa. Lahko jo razumemo kot del širšega koncepta sociologije doživljanja mesta, ki se osredotoča na to, kaj posameznik doživlja v krajih in prostorih ter z njimi (Borer, 2013: 966). Drug pomemben del tega pristopa je analiza senzoričnih zaznav javnih prostorov, tudi ulic, in njihovega ozračja ali vzdušja (Thibaud, 2011). Vzdušje je v tem smislu neločljivo povezano s čustvi, saj je opredeljeno kot zmožnost prostorov, da vplivajo na občutke (Löw, 2008).

Zaradi tovrstnega zaznavanja prostora in vzdušja v njem bi bilo treba razumeti, da je vzdušje pomemben del ulice kot kompleksnega družbenega pojava. Navedeno nakazuje, da bi bilo treba pri oblikovanju ali preoblikovanju mestnega prostora posebno pozornost nameniti možnostim vplivanja na vzdušje (tj. njegovega ustvarjanja ali poustvarjanja). Jean-Paul Thibaud (2015: 42) razlaga novo področje urbane intervencije: urbanistično oblikovanje se ne osredotoča več samo na predmete, ampak tudi na tisto, kar je med predmeti. Ne gre več samo za vprašanje oblikovanja stavb ali megaobjektov, ampak tudi tega, kar jih obdaja. Zato je ena izmed nalog arhitektov in odločevalcev, da se ne osredotočajo samo na funkcionalne ali estetske vidike, ampak tudi na občutke, ki jih najverjetneje vzbudijo spremembe javnega prostora. Navedeno se nanaša zlasti na gradnjo in obnovo, pri katerih lahko oblikovanje in preoblikovanje materialnih razmer vplivata na vzdušje na ulici in $\mathrm{v}$ povezavi $\mathrm{z}$ njim vzbudita negativne ali pozitivne občutke.

V članku avtorja proučujeta, kako spremenjena podoba ulice po prenovi vpliva na dojemanje ulice in vzdušja na njej. Pokažeta, da senzorično zaznavanje ulice pri ljudeh vzbuja negativna občutja in da prebivalci svoja negativna občutja, povezana $s$ sedanjo podobo ulice, običajno primerjajo s pozitivnimi spomini na nekdanjo ulico. Kot primer uporabita Tumsko ulico glavno ulico v srednje velikem poljskem mestu Plock.

\section{Glavna ulica in njene spremembe}

Nick Dines (2018: 953) za ulico uporablja izraz mikrokozmos mesta in ker ima ulica osrednjo vlogo v vsakdanjem življenju mestnih prebivalcev, bi bila lahko tudi kvazimetafora za mestno življenje. Nekateri raziskovalci trdijo, da ulica ponazarja naravo in dinamiko mesta, kar slikovito opiše tudi Henri Lefebvre (2003: 18): Ulica je kraj zbiranja (topos), saj brez nje niso mogoča nobena druga dogovorjena srečanja ... Na ulici kot nekakšni obliki spontanega gledališca postanem spektakel in včasih igralec. Ulica je kraj, kjer poteka gibanje - interakcija, brez katere ne bi bilo mestnega življenja ... Ulica je kraj igre in učenja. Ulica je kraj nereda.

Zanimiv in pomemben predmet raziskav ulic je glavna ulica. Izraz se nanaša na glavno nakupovalno ulico (ali včasih skupek več ulic) v mestnem središču, kjer so zgoščene trgovine in druge storitvene dejavnosti (Carmona, 2015). Glavna ulica ima pomembno vlogo v srednje velikih in majhnih mestih, saj zagotavlja občutek družbene stabilnosti in trajne lokalne identitete. Tradicionalno glavna ulica deluje kot prometno vozlišče in zbirališče, ki zagotavlja priročen dostop do trgovin in raznih storitev (Griffiths idr., 2008). Lahko pa se obravnava tudi kot čaroben prostor, ki ga radi obiskujejo tako prebivalci kot turisti, ki ustvarjajo in spodbujajo medosebne stike, poleg tega oblikuje posebne prostorske in čustvene odnose (Rzegocińska-Tyżuk, 2008).

Glavne ulice so v nekem trenutku izgubile svoj pomen. To je povezano s spremembami v mestnih središčih, ki jih običajno lahko opišemo kot degeneracija in propadanje. Navedena procesa sta se $\mathrm{v}$ zahodnih državah začela pojavljati konec tridesetih let 20. stoletja, vrhunec pa sta dosegla po letu 1960 (Robertson, 1995). Zaradi nenačrtnega širjenja mest (Burchell idr., 1998) in decentralizacije (Filion in Bunting, 2006) so mestna središča izgubila svoj pomen na račun predmestij, saj so se ljudje, trgovine in druge storitvene dejavnosti začeli seliti iz mestnih središč (Burayidi, 2001). Posledično so ljudje začeli soseske v središču mesta dojemati ne samo kot nepomembna, ampak tudi manj prijetna območja, na katerih živijo neprivilegirane skupine (starejši, priseljenci in izključeni posamezniki) (Neto idr., 2014). Poleg tega trgovska vloga glavnih ulic upada, pomen drugih mestnih prostorov, ki ponujajo najrazličnejše storitve (finančne, zabavne, zdravstvene itd.), pa narašča (Dawson, 1988). Razmere dodatno slabšajo čedalje večji stroški najema poslovnih prostorov, zaradi česar podjetja zapuščajo glavne ulice (Carmona, 2015). Posledično se te ulice ne dojemajo več kot naravna družbena središča mest.

Na neki točki je upadanje pomena glavnih ulic (tako kot propadanje mestnih središč) postalo družbeno in posledično politično vprašanje. Zato so bili izvedeni številni poskusi revitalizacije navedenih javnih prostorov (Anderson, 1964; Carmon, 1999; Seidman, 2004; Hechesky, 2005; Cerreta idr., 2018). Poleg splošnejših programov revitalizacije so bili uvedeni tudi konkretnejši pristopi k regeneraciji glavnih ulic. Med najbolj zna- 
nimi je ameriški program Main Street America (Internet 1), ki problem propadanja glavnih ulic obravnava $\mathrm{z}$ večdimenzionalnega vidika, pri čemer se osredotoča na vprašanja, kot so gospodarsko prestrukturiranje, organizacija, promocija in oblikovanje (Robertson, 2004). V mnogih primerih procesi revitalizacije niso dosegli pričakovanih rezultatov, kot so regeneracija skupnosti ali socialna in gospodarska rast mestnih središč (Kaźmierczak idr., 2011). Pogosto so navedeni procesi samo delno učinkoviti. Revitalizacija infrastrukture in podobe ulic je še najlažji del tovrstnih projektov, druge spremembe, kot je boj proti socialni izključenosti, izboljšanje kakovosti življenja prebivalcev ali gospodarska rast, pa je običajno mnogo težje doseči (Nowosielski 2012a, 2012b). Poleg tega so imeli nekateri programi regeneracije nepričakovane posledice: povzročali so gentrifikacijo (Cameron, 1992; Miciukiewicz, 2008), nekateri so vplivali na širjenje gospodarske neenakosti (Stern in Seifert, 2007), zaradi drugih pa je postala infrastruktura mestnih središč in glavnih ulic za prebivalce neudobna in neprijazna (Gehl, 2010).

\section{Občutenje mesta}

Vplivu revitalizacije na vzdušje na javnih prostorih se namenja le malo pozornosti, ob tem se (pozitivni ali negativni) občutki, ki jih vzbuja nova podoba ulice, le redko proučujejo. Analize s področja urbane sociologije se običajno bolj osredotočajo na negativne posledice revitalizacije, kot je gentrifikacija, okrepitev neenakosti ali nezmožnost aktivacije mestnih skupnosti. Vzdušju in občutkom bi bilo treba nameniti več pozornosti. $\mathrm{V}$ tem pogledu sta lahko koristna teoretična okvira, ki sta ju predlagala Thibaud oziroma Borer. V skladu s prvim bi se morala posebna pozornost nameniti vzdušju na mestnih prostorih. Mestni prostor omogoča številne ambiente, ki jib labko obcutimo $z$ usemi čutili. Ne glede na to, ali gre za živahno odprto tržnico ali pusto parkirišce, privlačno zgodovinsko jedro ali navadno postajo podzemne železnice, to, kako dojemamo te prostore, temelji na tem, kako jih senzorično doživljamo (Thibaud, 2011: 43). Ulica se tako ne dojema samo kot prostor, napolnjen z materialnimi predmeti ali ljudmi, ampak tudi kot prostor, ki omogoča, da ljudje v njem občutijo vse, kar jih obkroža. Navedeno ima posledice za raziskovalca, ki proučuje vzdušje na ulici. Thibaud (2011: 42) trdi, da pri zaznavanju javnega prostora ljudje ne vidijo stvari take, kot so, temveč občutijo nekakšno uglašenost z mestnim prostorom, ki jim omogoča, da mestni prostor doživljajo kot obcutenje sebe in sveta.

Drugi teoretični okvir pa temelji na sociologiji doživljanja mesta. Kot navaja Borer (2013: 969), labko vsak prostor v mestu ovrednotimo na podlagi čutnih dražljajev, ki jib vzbuja /.../Ti pomeni so $v$ plasteh naneseni na posamezen prostor, prav zaradi njihove zakoreninjenosti v posamezniku pa se oblikujeta identi- teta kraja in navezanost na kraj, ki ju posameznik deli z drugi$m i$. Navedena izjava ima dve pomembni posledici za nadaljnje raziskave. Prvič, nanaša se na čute, ki urejajo naše doživljanje vzdušja $\mathrm{v}$ javnem prostoru in našo uglašenost $\mathrm{z}$ njim. $\mathrm{Da}$ bi jih lahko analizirali, se moramo osredotočiti na to, kako ljudje zaznavajo prostor s čutili. Borer (2013: 969-978) s tem v zvezi predlaga analizo značilnosti mestnih krajin, ki jih zaznavamo z vidom, sluhom, vohom, okusom in tipom. Navedeno se ujema z razvrščanjem senzorično zaznanih območij, ki ga je predlagal Rodaway (1994) in razlikuje med značilnostmi območja, ki jih zaznavamo s tipom, vohom, sluhom in vidom.

Pri vidno zaznanih krajinah (ang. seescapes) je poudarjena vloga vida, s katerim lahko najlažje zaznavamo prostor. Poleg tega vizualni vidiki grajenega okolja vplivajo na doziviljanje mestnih prostorov tako, da ponujajo znake in namige, na podlagi katerih labko sklepamo, katere vrste interakcij tam potekajo in med kom (Borer, 2013: 970). Vidne značilnosti krajine zajemajo prvine, kot so oblika, barva, prostornina, velikost, zaporedje, raznolikost, predstavljivost in berljivost (Wankhede in Wahurwagh, 2016: 743). Vizualni vidiki se pogosto upoštevajo pri različnih strategijah revitalizacije javnega prostora (Hubbard, 1996). Pri krajinah, ki jih zaznavamo s sluhom (ang. soundscapes), je poudarek na dejstvu, da je mesto polno zvokov, ritmov in hrupov različne intenzivnosti in glasnosti, ki prihajajo iz različnih virov, kot so ulični promet, javni prevoz, industrijske cone in ljudje. Nekatere mešanice različnih zvokov so povezane s posameznimi kraji (Borer, 2013: 971). Krajine, ki jih zaznavamo z vonjem (ang. smellscapes), se nanašajo na vohalne zaznave in njihovo interpretacijo, zlasti v smislu sprejemljivih in nesprejemljivih vonjev, ki so običajno povezani s tem, kaj je družbeno zaželeno in nezaželeno. Omeniti je treba, da je za nekatere kulture, tudi evropsko, značilen poseben pojav upravljanja vonjav, katerega cilj je doseči prostore brez vonja (Waskul in Vannini, 2008: 55-56). Opisane krajine lahko na primer opredelimo tudi na podlagi razlikovanja med aromatičnimi, dišečmi, česnovimi, ambrozijskimi, kozjimi, odbijajocimi, odvratnimi in podobnimi vonji (Wankhede in Wahurwagh, 2016: 743). Krajine, ki jih zaznavamo $\mathrm{z}$ okusom (ang. tastescapes), se nanašajo na proces doživljanja mesta prek pripravljanja in uživanja hrane in pijač. Poudarek je na zaznavah sladkosti, kislosti, slanosti in grenkosti (Wankhede in Wahurwagh, 2016: 743). Krajine, ki jih zaznavamo $s$ tipom (ang. touchscapes), je verjetno najtežje opisati, ker se zdi, da niso omejene samo na zaznavanje teksture površin $s$ prsti (Rodaway, 1994: 44), ampak so povezane $s$ kompleksnejšim doživljanjem, ki vključuje premikanje skozi prostore in med predmeti ter njihovo občutenje s celotnim telesom. Med drugim obsegajo občutke subosti, hladnosti, hrapavosti in trdote (Wankhede in Wahurwagh, 2016: 743). To je povezano z ugotovitvijo, da čutno doživljanje krajev ni individualno, ampak prej skupno. Zato bi ga lahko proučevali ne samo indi- 
vidualno, ampak tudi v razmerah, $\mathrm{v}$ katerih bi lahko analizirali njegovo kolektivno naravo.

\section{Tumska ulica v Plocku}

Tumska ulica leži v starem mestnem jedru Plocka - srednje velikega industrijskega mesta v osrednjem delu Poljske, v katerem živi približno 120.000 ljudi. Ulica je bila na začetku 19. stoletja znana kot Dohm Straße (slo. Stolna ulica) in je bila zgrajena v središču mesta kot povezava med trgoma Rynek Kanoniczy (slo. Kanonični trg) in Nowy Rynek (slo. Novi trg) (Rydzewska, 2009). Čeprav je gradnja trajala pol stoletja, je zaradi oblike in središčne lokacije $\mathrm{v}$ mestu postala glavna ulica. Sprva je bila pomembna prometna pot, sčasoma pa je začela opravljati tudi druge funkcije (tj.., stanovanjsko, storitveno in trgovsko). Trgovska funkcija je postala pomembnejša na prelomu 19. v 20. stoletje, ko si je Tumska ulica prizadevala postati nakupovalno središce mesta (Rydzewska, 2009: 24). Postopno je prevzela tudi vlogo kulturnega in družabnega središča Plocka, ki je med prebivalci vzbujalo pozitivne občutke.

Prebivalci Plocka, ki se ulice spominjajo še iz predvojnega obdobja, o njej govorijo kot o živahni ulici, ki je spodbujala preživljanje časa na prostem. Takratni Hotel Angielski, ki ga danes ni več, je bil zbiralǐ̌če, kjer so ljudje pokušali lokalna vina in plesali. Ulica je bila prostor, kjer se je odvijalo družabno življenje (Luma, 2009). Umetniški klub, kjer so se zbirali boemi, in škofijska katoliška hiša s kinom in gledališ̌cem za 1.500 ljudi, odprta leta 1935, sta zagotavljala zabavo in razvedrilo manj premožnim meščanom (Rydzewska, 2009). Po drugi svetovni vojni se je zaradi prilagoditev, ki jih je zahteval novi socialistični sistem, narava ulice spremenila. Zgrajene so bile nove javne stavbe, večina katerih je bila povezana s trgovino (blagovnica Centrum) in gostinstvom (gostilna Piast oziroma poznejši koktejl bar Hortex) (Rydzewska, 2009). Komunistična oblast je slikoviti Hotel Angielski spremenila v krojaško zadrugo, kulturni center (nekdanja katoliška hiša) na Tumski ulici pa je ostajal zbirališče umetnikov in središče kulturnega življenja, zlasti, ker je bil v njegovih prostorih tudi kino Przedwiošnie. Poleg tega se je postopno spremenila tudi sestava prebivalcev Tumske ulice: premožne meščane in lastnike značilnih večstanovanjskih stavb, zgrajenih iz opeke ali kamna (pol. kamienice), so zamenjali pripadniki nižjih družbenih slojev (Luma, 2009). $\mathrm{Na}$ začetku sedemdesetih let 20. stoletja je bila ulica prvič prenovljena, in sicer je bila preurejena $\mathrm{v}$ pešcono $s$ kotički za sprostitev, ozelenjenimi z rožami in drevesi. Navedene spremembe so med prebivalci vzbujale mešane občutke (Rydzewska, 2009). Po letu 1989 je zaradi prehoda države v tržno gospodarstvo začela cveteti trgovska funkcija ulice, med ljudmi pa se je še okrepila predstava o njej kot o živahnem trgovskem središču mesta. Hkrati so se v mestu gradile nove stavbe, ki so

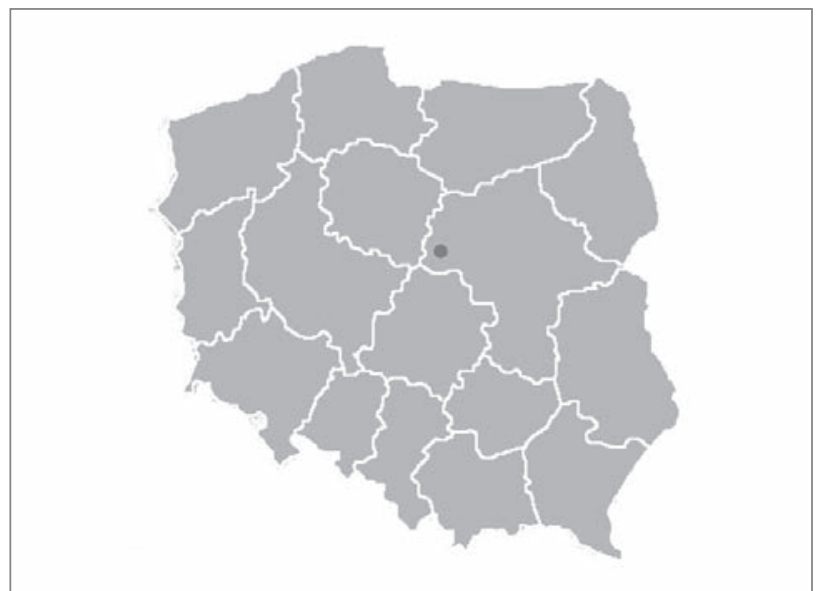

Slika 1: Plock na zemljevidu Poljske (vir: Internet 2)

delno nadomestile stare propadajoče objekte in so se ujemale $s$ prvotnimi meščanskimi stavbami (Rydzewska, 2009). V prvem desetletju 21. stoletja so v Plocku hitro nastajali novi nakupovalni centri, zaradi česar so kupci zapuščali Tumsko ulico, ki je $s$ tem izgubljala vlogo nakupovalnega središča mesta. Hkrati so mestne oblasti dale pobudo za projekt njene posodobitve, ki je bil dokončan leta 2006. Leta 2007 je prejel glavno nagrado na državnem natečaju posodobitve leta, mestne oblasti pa so prenovljeno ulico začele oglaševati pod reklamnim geslom dnevna soba mesta. Uveden je bil tudi program subvencioniranja prenove starih večstanovanjskih stavb (Woźniak, 2008). Razen sprememb $\mathrm{v}$ tlaku, ulični opremi in zelenih površinah nadaljnji posegi kljub temu niso bili v celoti izvedeni. Poleg tega prenova ni bila samo množično kritizirana, ker je med prebivalci vzbujala močne negativne občutke (Woźniak, 2008; Tybura, 2019), ampak tudi ni zmogla zaustaviti družbenega nazadovanja ulice in upada njenega pomena $\mathrm{v}$ očeh prebivalcev. Leta 2012 so Tumsko ulico imenovali celo bančna ulica, saj je bilo na $326 \mathrm{~m}$ dolgem območju za pešce kar dvajset bančnih poslovalnic. Primanjkovalo je kavarn, trgovin in predvsem pešcev, kar je dajalo vtis prazne, zapuščene ulice (Woźniak, 2008; Marciniak, 2012).

Do zdaj se položaj ni kaj dosti spremenil. Ulica ostaja predvsem promenada, ki se razteza do Tumskega hriba (pol. Wzgórze Tumskie). Zdi se, da je izgubila svoj nekdanji pomen trgovskega, zabavnega in kulturnega središča mesta (Tybura, 2019), kljub temu pa ostaja pomembna čustvena referenčna točka. Ewa Luma (2009: 59) glede tega, kako Tumsko ulico doživljajo starejši prebivalci Plocka, navaja: Tumska ulica ima pomembno preteklost, pred nami pa je, upamo, velicastna prihodnost. Ali bo postala dnevna soba mesta, bodo pokazala naslednja stoletja. Ljudje, ki se po njej sprehajajo, so njeno življenje. Njena narava je sestavljena iz številnih prvin: stavb (biš), dvorišc, ulic in oken stanovanj, vkaterih živijo ljudje. Prebivalci so srce vsakega mesta. Hiše so samo njena zunanja podoba, medtem ko ulico dolocajo ljudje in njihovi obcutki. 


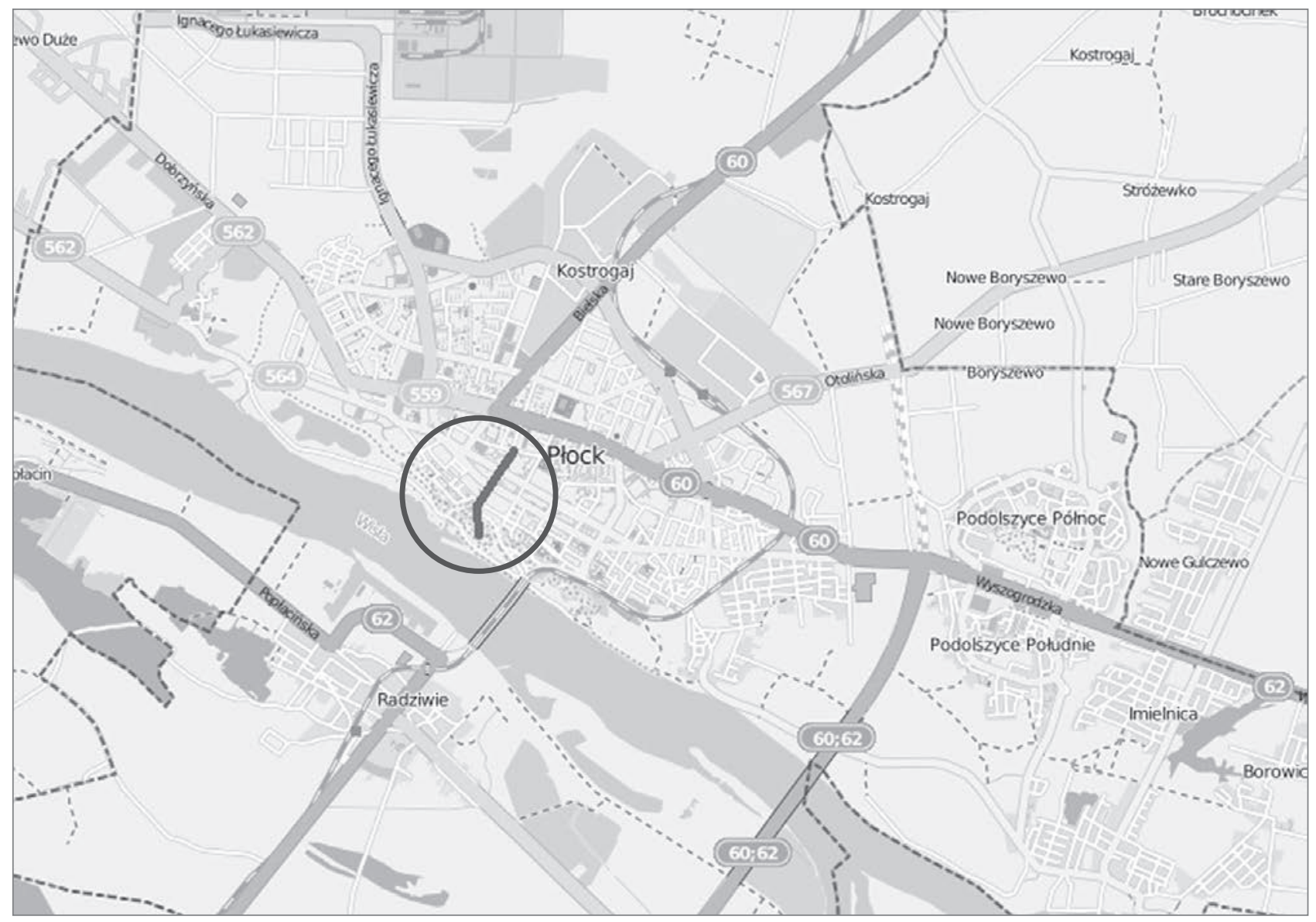

Slika 2: Tumska ulica v Plocku (vir: Internet 3)

\section{Raziskovalna metoda in podatki}

Raziskava, predstavljena $\mathrm{v}$ tem članku, temelji na analizi podatkov iz mnenj, pridobljenih leta 2018 v okviru dveh fokusnih skupin, v katerih so sodelovali prebivalci Plocka. V vsaki skupini je bilo po osem posameznikov, ti pa so bili izbrani z namenskim vzorčenjem na podlagi čim večjih razlik med seboj. Za raziskavo so bili tako izbrani posamezniki različne starosti, izobrazbe in poklica. Drugo merilo za vzorčenje je bil kraj bivanja: $\mathrm{v}$ fokusnih skupinah so tako sodelovali prebivalci različnih predelov Plocka. Raziskava z obema fokusnima skupinama je potekala v stavbi Mazovijske državne univerze, ki ni v središč mesta, ampak v eni izmed stanovanjskih sosesk v Plocku. Raziskava s prvo fokusno skupino je trajala 1 uro in 26 minut, $z$ drugo pa 1 uro in 40 minut.

V raziskavi s fokusnima skupinama je bilo obdelanih po šest tem, med drugim so si morali člani skupin zamisliti, kako se sprehajajo po sedanji Tumski ulici, in opisati, kaj pri tem občutijo. Prvi sklop vprašanj je bil uporabljen kot ogrevanje in se je večinoma nanašal na podatke o sodelujočih $v$ raziskavi: njihovo socialno-demografsko ozadje, kraj bivanja v Plocku in njihov odnos do Tumske ulice. Drugi sklop vprašanj je temeljil na projekcijskih tehnikah, s katerimi sta želela avtorja raziskave določiti občutke sodelujočih $\mathrm{v}$ raziskavi $\mathrm{v}$ povezavi $s$ Tumsko ulico in vzdušjem na njej ter njihovo uglašenost z ulico. Pri spraševanju je moderator anketirance pozval, naj zaprejo oči, si zamislijo, kako se sprehajajo po Tumski ulici, in pri tem opišejo svoje občutke. Izkazalo se je, da je bila navedena tehnika med udeleženci zelo dobro sprejeta, njihovi odgovori pa so zagotovili zanimive podatke o tem, kako dojemajo vzdušje na ulici. Tretji tematski sklop raziskave se je nanašal na vsakdanje stike s Tumsko ulico. Sodelujoči v raziskavi so morali povedati, kolikokrat na dan jo obiščejo in zakaj (in če je ne obiskujejo, zakaj ne). Naslednji sklop vprašanj se je osredotočal na dogodke, organizirane na Tumski ulici, in kako jih vprašani dojemajo, peti sklop pa na zaznane prednosti in slabosti ulice. Pri zadnjem sklopu vprašanj pa so morali sodelujoči v raziskavi opisati, kako bi bila videti idealna Tumska ulica.

V članku se avtorja osredotočata na zaznavanje Tumske ulice in vzdušja na njej. Pri njuni analizi je poudarek na štirih kategorijah senzoričnega zaznavanja krajine, kot jih je predlagal Borer (2013), ter na spominih na nekdanjo ulico in posledicah prenove na to, kako jo ljudje zaznavajo. Uporabljena raziskovalna metoda je vključevala delo $s$ fokusnima skupinama kot orodje, ki omogoča večjo angažiranost sodelujočih. Pri taki 


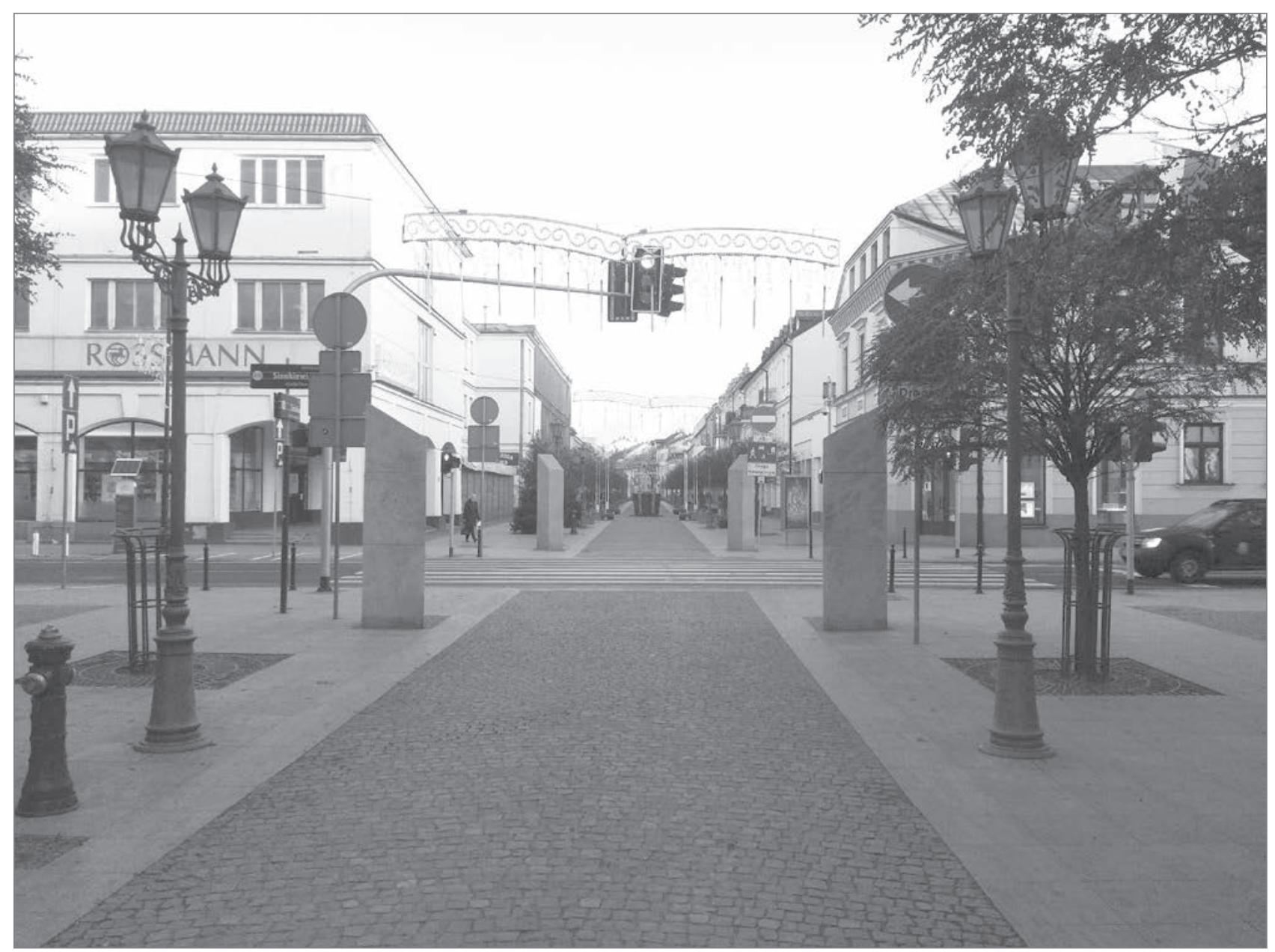

Slika 3: Kamnita Tumska ulica (foto: Michał Nowosielski)

skupinski raziskavi se lažje odprejo in navežejo stik z drugimi. Poleg tega navedena metoda udeležence spodbuja, da delijo svoje občutke in čustva (Gawlik, 2012) ter se o njih pogovarjajo. Navedeno pa je mogoče doseči samo, če vprašanja, ki se obravnavajo, niso preveč problematična ali intimna.

\section{Rezultati}

Vprašanja o zaznanem vzdušju na Tumski ulici so se izkazala za zelo učinkovita pri pridobivanju informacij o občutkih sodelujočih v raziskavi. Številni odgovori in razprave, ki so sledile, so se nanašali na čutne, skoraj telesne zaznave, ki jih po Borerju (2013) lahko razdelimo v štiri vrste senzoričnega zaznavanja: tipno, vidno, slušno in vohalno. Zaznavanje krajine, ki se nanaša na okus, v raziskavo ni bilo vključeno.

Spodnji primeri izjav vprašanih so šifrirani na naslednji način: če je navedena izjava samo enega sodelujočega $v$ raziskavi, je označena $s$ številko fokusne skupine in številko te osebe (npr. FS1S4), če pa gre za izmenjavo mnenj med več sodelujočimi v raziskavi, je vsaka izjava označena s številko ose- be, celoten pogovor pa je označen $s$ številko fokusne skupine. Vprašanje moderatorja je označeno s številko fokusne skupine in črko M (npr. FS2M).

\subsection{Tipno zaznavanje krajine}

Najpogosteje omenjeni občutek je bil hlad, zaradi česar so se sodelujoči v raziskavi počutili zelo neprijetno:

FS1S4: Naj se sliši še tako čudno, čutim hlad in praznino. FS2S7: Čutim hladno vzdušje.

FS1S7: Zanimivo, tudi jaz sem občutil hlad. Prva beseda, na katero sem pomislil, je bil hlad.

Med pogovorom so sodelujoči v raziskavi dodatno pojasnili razloge za opisani občutek. Mnogi so dejali, da so vzrok za hladnost Tumske ulice materiali, iz katerih je zgrajena. Konkretno so omenjali material, $s$ katerim je tlakovana, ter obliko in materiale ulične opreme. Opozorili so predvsem na prevlado kamna. 


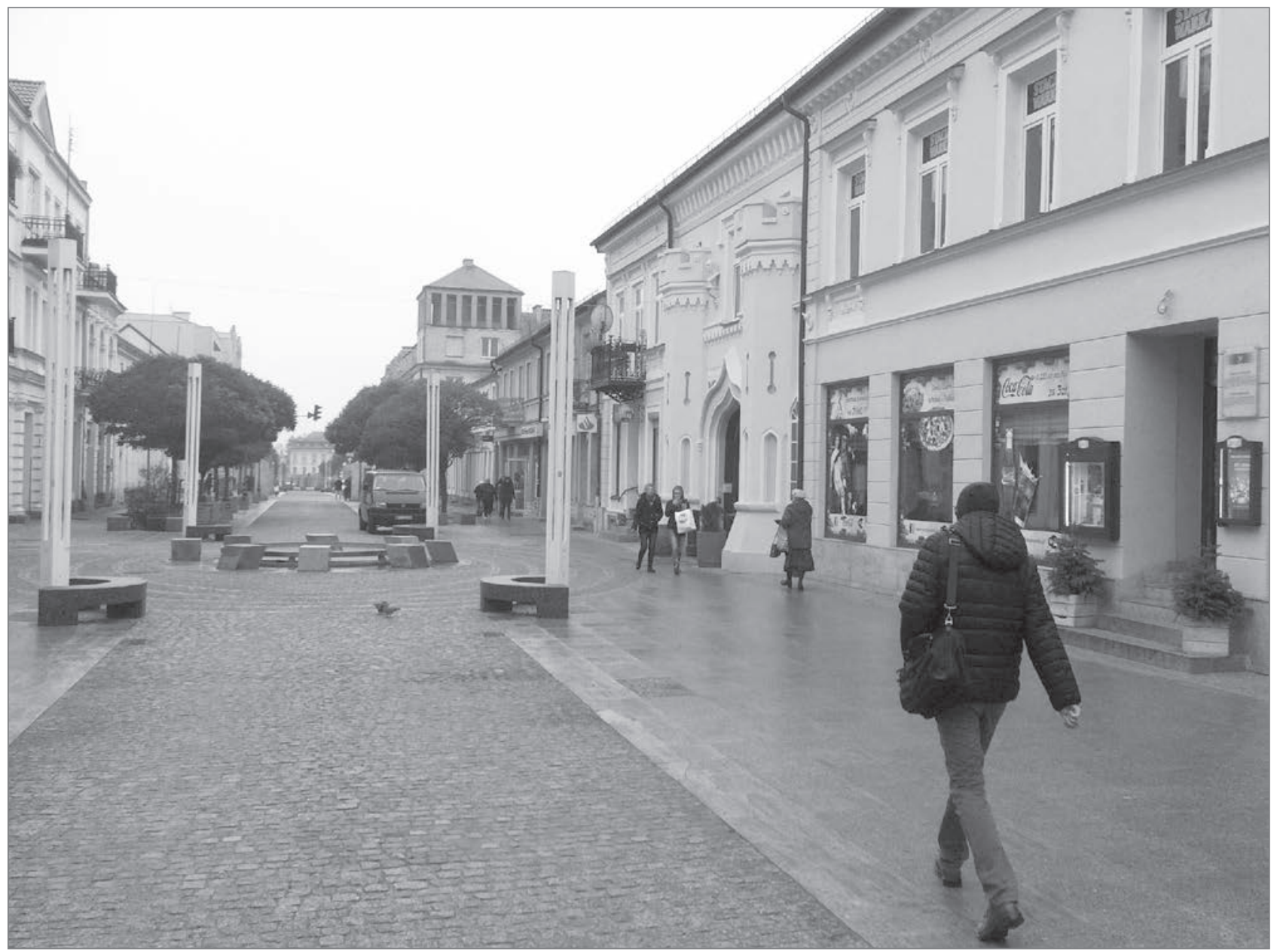

Slika 4: Različna površina in pešci na pločnikih Tumske ulice (foto: Michal Nowosielski)

FS2: M: Hlad? Zakaj ga čutite? Od kod prihaja?

S5: Mislim, da iz materialov, iz katerih je ulica zgrajena.

S2: Ja!

S5: Točno tako. Ti tlakovci ...

S1: Te kamnite klopi.

S6: Vse je tako hladno.

S1: Kamniti oglasni stebri. O tem govorite?

S5: Ja. Vse je tako ... Ni nobene spontanosti.

Zdi se, da zlasti ulična oprema in tlakovci pri vprašanih vzbujajo zelo močne občutke. Vidik, ki je pritegnil njihovo posebno pozornost, je različna površina ulice, $\mathrm{z}$ gladkimi ploščami ob straneh in neravnimi tlakovci v sredini. Poleg tega, da jo vprašani občutijo kot hladno, jo zaznavajo tudi kot neudobno in nefunkcionalno. Zanimivo je, da so sodelujoči v raziskavi svoje občutke opisovali z izrazi, ki so poudarjali spolzkost ali neenakomernost talne površine.

FS2: S4: Površina ni v redu. Ni ravna. Ko se mi mudi z avtobusa v službo in hodim hitro, je na teh tlakovcih težko. Zlasti ko je spolzko.
M: Sestavljena je iz različnih delov.

S2: Ja. In ko hodim, raje hodim ...

S1: Ob strani, ker je lažje.

S2: Tako je, ker so v sredini tako veliki tlakovci. Priznam pa, da se po sredini vozim $s$ kolesom, ker je tam manj ljudi.

S7: [Robovi] so pozimi spolzki. Pozimi se je bolje držati sredine.

Sodelujoči v raziskavi so opozorili še na kamnito in hladno ulično opremo. Navedene čutne zaznave nakazujejo, da po mnenju ljudi ulična oprema ne opravlja svoje vloge. Vprašani so najpogosteje omenjali klopi, na katerih naj bi sedeli, počivali in se pogovarjali, po njihovem mnenju niso samo neudobne, ampak tudi nefunkcionalne. Opisali so jih kot uporabniku neprijazne in poudarili, da pozimi postanejo še hladnejše, poleti pa še bolj vroče.

FS1: S1: Gole so. Povsod je samo kamen, ki je zelo neprijazen, saj so ta sedišča ...

S7: Popolnoma nefunkcionalna.

S2: Ne spodbujajo te $k$ temu, da nanje sedeš ne poleti ne pozimi, ker so ali prevroča ali premrzla. 

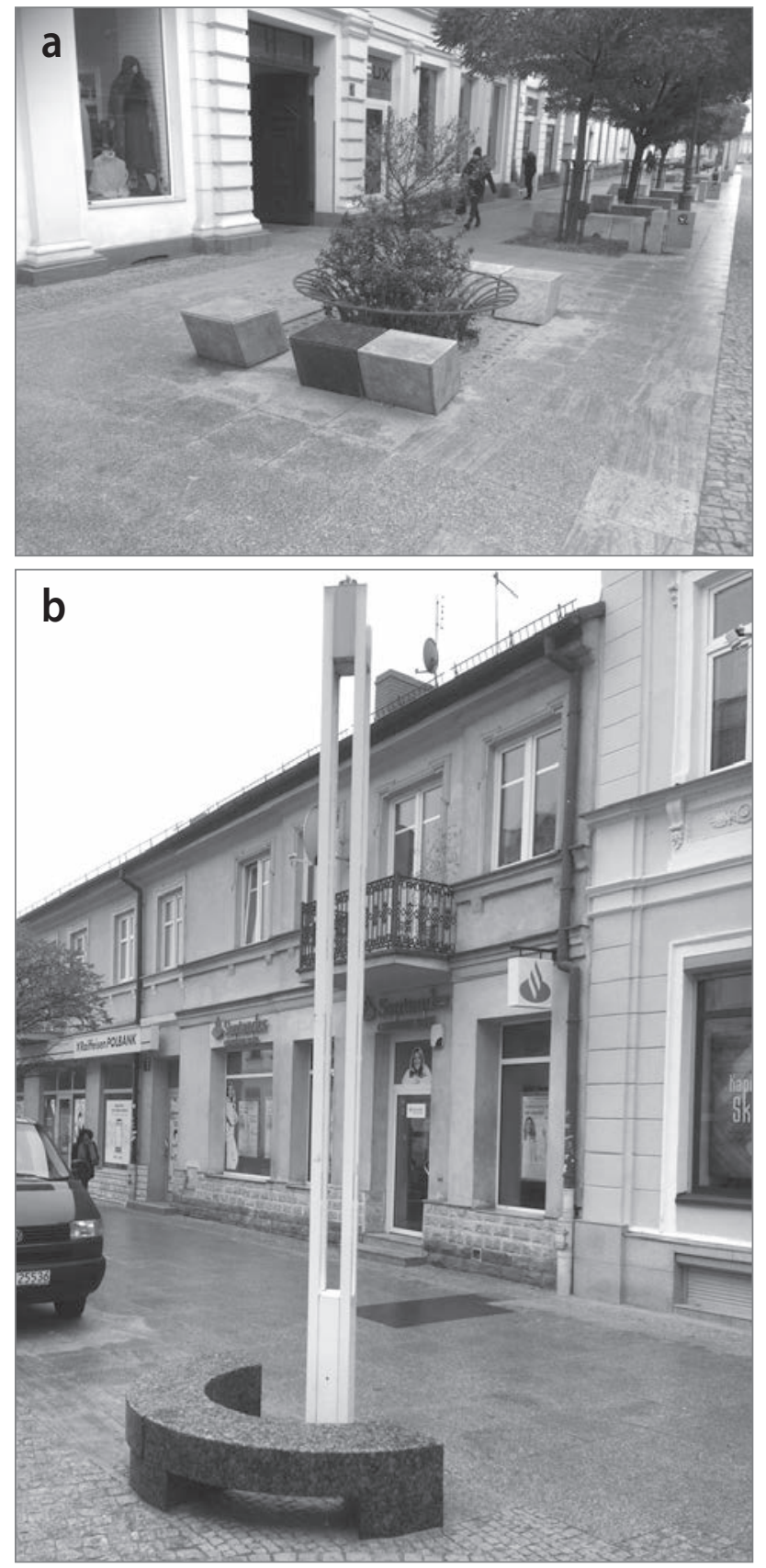

Sliki 5a in 5b: Klopi na Tumski ulici (foto: Michal Nowosielski)

\subsection{Vidno zaznavanje krajine}

Poleg občutka hladnosti so sodelujoči v raziskavi pogosto omenjali občutek praznosti in opustelosti. Večina je medtem, ko si je zamišljala, da hodi po ulici, navajala, da ni tam nikogar drugega.

FS1S5: Praznost. Na žalost nisem videl nikogar, ki bi šel mimo mene.

FS2S1: Na Tumski ni ljudi.
Nekateri sodelujoči $\mathrm{v}$ raziskavi praznosti niso povezovali z družbenimi dejavniki (da ni ljudi), ampak z arhitekturno obliko ulice. Spet se je omenjala kamnitost, poleg pomanjkanja dreves in splošnega občutka praznosti ulice.

FS1S4: Kamnita puščava, to je moja prva asociacija.

\subsection{Slušno zaznavanje krajine}

Sodelujoči v raziskavi so pogosto povezovali občutek hladu in praznosti, pri čemer so nekako poskušali pojasniti enega $\mathrm{v}$ povezavi z drugim. Poleg tega so omenjali še en občutek, ki močno vpliva na vzdušje na ulici: tišno. Pri tem so vprašani govorili predvsem o tem, da ni običajnega uličnega hrupa.

FS2S4: Mislim, da hlad ulice ... izvira iz dejstva, da preprosto na njej ni ljudi, da je tako prazna in opustela, ko se po njej sprehodiš.

FS2S7: Verjetno je to najpomembnejše ... Na splošno ni ljudi, ni tega utripa in uličnega hrupa, zaradi katerega bi ulica takoj postala prijetnejša.

\subsection{Vohalno zaznavanje krajine}

Zadnja in najmanjkrat omenjena čutna zaznava je bil vonj. Nekateri vprašani so pri tem, ko so si zamišljali, da hodijo po ulici, poročali o tem, da zaznavajo neprijeten vonj po dimu iz peči, te namreč nekatera gospodinjstva uporabljajo za ogrevanje.

FS2S5: Zadušljiv dim iz dimnikov. Zelo neprijeten občutek.

\subsection{Vzdušje na Tumski ulici, kot se ga spominjajo ljudje}

Nekateri sodelujoči v raziskavi so svoje današnje neprijetne občutke primerjali s spomini na čase, ko so bili ti dosti prijetnejši. Pogosto so primerjali hlad $s$ toploto in praznost $s$ prijetnim občutkom družabnosti. Eden izmed vprašanih je razliko med nekdanjo in sedanjo Tumsko ulico primerjal $\mathrm{z}$ razliko med živim in mrtvim.

FS1S4: Še vedno se spominjam nekdanje Tumske. Bila je povsem drugačna. Seveda je bila zanemarjena in ni bila lepa. Bila je malo za časom, kot da bi bila iz nekega drugega obdobja, a je imela neko posebno vzdušje. Vzdušje na njej je bilo povsem drugačno. Na njej so rasla velika, lepa, zelena drevesa z velikimi krošnjami. Vmes so bile nišs s klopmi, kamor si se lahko usedel. Ljudje so si kupili tortico ali sladoled in se tam ustavili ali pa so se usedli in se pogovarjali. Različni ljudje - ne samo izobraženci, ampak tudi navadni ljudje, ki so živeli v bližini. Tumska je takrat preprosto živela. 


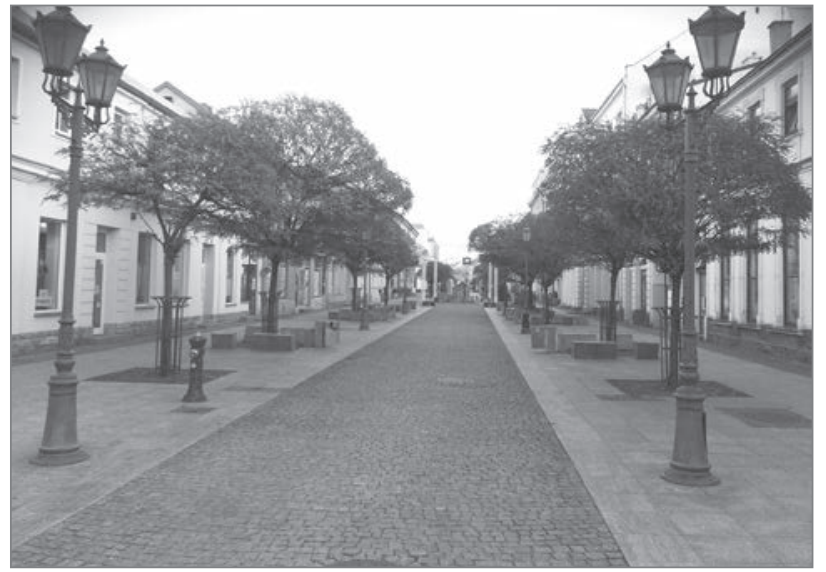

Slika 6: Opustela Tumska ulica (foto: Michal Nowosielski)

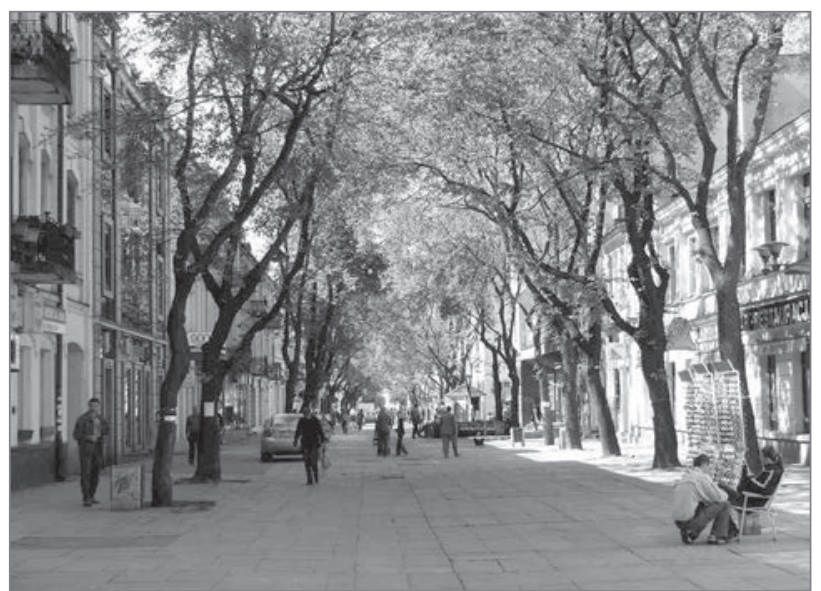

Slika 7: Tumska ulica pred revitalizacijo (foto: Mariusz Kucharczyk)

Ko so bili udeleženci raziskave vprašani, kdaj se je po njihovem mnenju zgodila ta sprememba, so vedno poudarili, da po revitalizaciji. Zaradi prenove naj bi se spremenila narava ulice, ki je postala neprijazna pešcem. Zanimivo je, da se je nova, bolj estetska oblika ulice izkazala za čustveno manj sprejemljivo. Vprašani so pogosto poudarili, da je bila celotna prenova Tumske ulice bolj umetniška vizija arhitekta kot pa odgovor na družbene potrebe in pričakovanja.

FS1S2: Šokiran sem bil, ko sem videl Tumsko po prenovi. Ali si opazil? Nekoč je bila polna dreves, tako da sploh nisi mogel videti nič drugega, če si nanjo ...

S4: Pogledal ...

S2: Točno. Po prenovi pa sem enkrat pogledal tja in videl, da je vse prazno.

FS1S6 Mislim, da je problem pristop, ki ga je arhitekt uporabil ... Kot da bi stanovanje opremil v zelo sodobnem slogu, vendar je to storil samo zase, da bi izpolnil vizijo, ki jo je imel $\mathrm{v}$ mislih. To mu je pomagalo pri karieri in za projekt je celo prejel nagrade, vendar s tem ni pomagal nikomur drugemu.

Izjavam, v katerih so sodelujoči v raziskavi opisovali negativne občutke $\mathrm{v}$ povezavi $s$ prenovo, so običajno sledile splošnejše

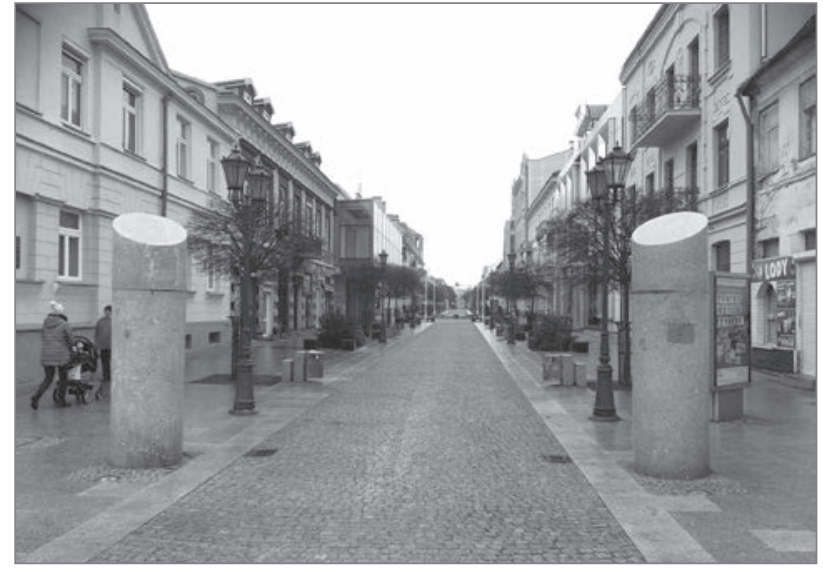

Slika 8: Pogled na Tumsko ulico (foto: Michał Nowosielski)

opazke glede tega, komu naj bi bili ulica in njena prenova namenjeni. Pri tem so vprašani znova omenjali močne negativne občutke, ki jih je v njih vzbujala prenova. Prenovljeno Tumsko ulico namreč dojemajo kot razčlovečeno, neprijazno in celo neprimerno za življenje, zaradi česar se na njej zadržujejo samo, če je to res nujno. Tumska ulica se tako uporablja samo kot povezava z drugimi ulicami in mestnimi prostori.

FS1S4: Komu naj bi bila namenjena? Mesto je namenjeno njegovim prebivalcem. Mesto je namenjeno nam in moralo bi biti funkcionalno in prijazno ter spodbujati bi moralo preživljanje časa na prostem. Tumska ulica še zdaleč ni takšna, ljudi celo odbija. Vsi komaj čakajo, da jo prečkajo in zapustijo.

FS1S4: Tumska je preprosto hladna, kamnita, razčlovečena, neprijazna pešcem ... Ni primerna za življenje.

FS1S7: Ulica se uporablja samo kot prehod.

\section{Razprava}

Kot predpostavlja Thibaud (2015: 42), bi se moralo oblikovanje osredotočati na občutke in vzdušje, pri čemer naš namen ni preoblikovati samo svet grajenih objektov, ampak tudi svet ozračja in zaznavnega vzdušja. Tovrstna naloga pa zahteva osredotočenost na občutke, ki jih vzbujajo javni prostori in se vzbujajo na javnih prostorih. Zlasti težavna je pri prenovi javnega prostora, kot je na primer glavna ulica, ki ima velik družben in čustven pomen. Arhitekt mora namreč upoštevati tako pričakovanja odločevalcev kot močno uveljavljena mnenja in občutke, ki so jih prebivalci oblikovali na podlagi dolgoletnih osebnih izkušenj.

Analiza raziskave s fokusnima skupinama kaže, da Tumska ulica pri udeležencih zbuja močne občutke v povezavi z vsemi štirimi proučevanimi vidiki: tipnim, vidnim, slušnim in vohalnim zaznavanjem krajine (glej Preglednico 1). Pri tipnem zaznavanju krajine so sodelujoči v raziskavi pri opisovanju splošnega vzdušja na ulici in njenih posameznih prvin govorili o hladu, 
Preglednica 1: Zaznani občutki na Tumski ulici in vrste senzoričnega zaznavanja

\begin{tabular}{|c|c|c|c|c|}
\hline & Vrsta senzoričnega zaznavanja & & & \\
\hline \multirow[t]{5}{*}{ Opis občutka } & Tipno & Vidno & Slušno & Vohalno \\
\hline & Hlad & Praznost & Tišina & Preveč dima \\
\hline & Spolzkost & Opustelost & Brezšumnost & Smrad \\
\hline & Neravnost & & & \\
\hline & Neprijaznost uporabniku & & & \\
\hline
\end{tabular}

ob tem pa so omenjali tudi spolzka in neravna tlakovana tla ali uporabniku neprijazno ulično opremo. Pri vidnem zaznavanju krajine so opisovali občutke praznine in ulico primerjali s puščavo, pri slušnem zaznavanju krajine so omenjali pomanjkanje običajnega uličnega hrupa, pri vohalnem zaznavanju krajine pa so poudarjali vonj po dimu.

Vsi štirje vidiki oblikujejo hladno, kamnito in razčlovečeno vzdušje in senzorično zaznavanje današnje Tumske ulice. Tovrstni občutki pa se še okrepijo ob spominih na nekdaj toplo, obljudeno ulico, ki je vzbujala pozitivna čustva. Zdi se, da navedeno potrjuje domnevo Paula Rodawaya (1994), da se zaznavanje ne nanaša samo na sprejemanje informacij, ampak tudi na miselne uvide, sestavljene iz senzoričnih informacij, spominov in pričakovanj. Zaradi nasprotja med pozitivno podobo nekdanje Tumske ulice in precej negativnim doživljanjem njene sedanje podobe je senzorično zaznavanje ulice tako zelo negativno - verjetno še bolj, kot bi pričakovali na podlagi njene objektivne oblike. Primer Tumske ulice v Plocku poleg tega kaže, kako lahko prenova, katere cilj je revitalizirati pomemben javni prostor, povzroči nepričakovane in nezaželene posledice s tem, ko nepopravljivo okrni ulično vzdušje. Prostorske spremembe, ki jih je povzročila prenova, med prebivalci vzbujajo močne negativne občutke, ki jih opisujejo na podlagi intenzivnih čutnih zaznav.

Zaznave uličnega vzdušja in občutki prebivalcev kažejo, da posledice prenove niso omejene samo na psihološke ali čustvene vidike. Kot navajata Kalyani Wankhede in Amit Wahurwagh (2016), pozitivne in negativne čutne zaznave mestnih prostorov močno vplivajo na kakovost javnih krajev. Zaradi njih lahko začnejo ljudje tudi sebe drugače dojemati v tem prostoru (npr. da pripadajo ali ne pripadajo kraju, da so na pravem ali napačnem kraju itd.), poleg tega lahko vplivajo na njihove odločitve glede njegove uporabe. Če je vzdušje na ulici negativno ali če ulica vzbuja neprijetne občutke, se spremenijo tudi aktivnosti, ki jih prebivalci na njej izvajajo, pri čemer jo uporabljajo samo, če je to res nujno. Če uporabimo besede Jana Gehla (2010), se Tumska ulica uporablja samo za nujne, funkcionalne aktivnosti ali aktivnosti, v katere so ljudje prisiljeni ( $\mathrm{tj}$. kot povezovalna ulica z drugimi ulicami ali pomembnimi mestnimi prostori). Hkrati so druge, manj nujne aktivnosti (npr. rekreacija in druženje z drugimi) močno omejene.

\section{Sklep}

Pri oblikovanju ali preoblikovanju javnih prostorov je treba vedno upoštevati, da dobro načrtovani in oblikovani prostori ljudi spodbujajo, da se družijo z drugimi zunaj svojega doma, saj pri njih vzbujajo pozitivne občutke, medtem ko slabo oblikovani prostori pri ljudeh vzbujajo negativne občutke in jih odvračajo od druženja zunaj. Izsledki raziskave potrjujejo, da so pri tem ključne čutne zaznave. Pri načrtovanju revitalizacije ali prenove se je zato treba nasloniti na raziskave senzoričnega zaznavanja, ki upoštevajo vse vrste čutnih zaznav ter spomine in pričakovanja prebivalcev. Tovrstne raziskave so lahko v pomoč pri odločanju (Battistini in Mondino, 2017; El-Sayyad, 2019). Hkrati se je pomembno zavedati vrzeli med značilnimi ukrepi strokovnjakov (npr. arhitektov), ki temeljijo na estetskih in funkcionalnih merilih, ter ljudskimi ukrepi prebivalcev, ki se bolj osredotočajo na občutenje prostora in uglašenost z njim. Izsledki raziskave kažejo, da je treba upoštevati oboje. Prejšnje študije razkrivajo, da obstajajo primeri revitalizacije, pri katerih je bila upoštevana pomembna vloga čutnih zaznav (Degen, 2004; Brown, 2012; Henshaw, 2013).

Primer, predstavljen v tem članku, kaže, da so lahko vzdušje, občutki in čutne zaznave uporabni raziskovalni kazalniki na področju sociologije doživljanja mesta in lahko pomagajo razumeti, kako ljudje dobro sprejemajo javni prostor. Treba pa bi bilo opraviti širše raziskave z več primeri in raznimi raziskovalnimi metodami. Čeprav se je raziskava s fokusnima skupinama v tem primeru izkazala za učinkovito orodje, bi jo bilo treba $\mathrm{v}$ nadaljnjih raziskavah podpreti z drugimi tehnikami, vključno s posebno metodologijo, ki bi temeljila na senzoričnih sprehodih (vohalnih, slušnih sprehodih itd.), zapisovanju zaznav in interpretacij zaznanih občutij ter izdelavi senzoričnih zemljevidov (El-Sayyad, 2019). Z navedenim postopkom bi pridobili pomembne informacije o čutnem zaznavanju javnega prostora, na podlagi česar bi ga lahko ustrezno oblikovali ali preoblikovali.

Michal Nowosielski

Mazowiecka Uczelnia Publiczna w Płocku (Mazovijska državna univerza v Plocku), Plock, Poljska

E-naslov:m.nowosielski@mazowiecka.edu.pl 
Agnieszka Nowosielska

Mazowiecka Uczelnia Publiczna w Płocku (Mazovijska državna univerza v Plocku), Plock, Poljska

E-naslov: a.nowosielska@mazowiecka.edu.pl

\section{Zahvala}

Raziskava je bila financirana v okviru projekta Tumska na nowo badania, katerega naročnik je bila mestna občina Plock, izvajal pa se je na Mazovijski državni univerzi.

\section{Viri in literatura}

Anderson, M. (1964): The federal bulldozer. Cambridge, MA, MIT Press.

Battistini, E., in Mondino, M. (2017): For a semiotic multisensorial analysis of urban space. The case of Ballaro and Vucciria markets in Palermo. Punctum, 3(1), str. 12-26.

Brown, A. L. (2012): A review of progress in soundscapes and an approach to soundscape planning. International Journal of Acoustics and Vibrations, 17(2), str. 73-81.

Borer, M. I. (2013): Being in the city: The sociology of urban experiences. Sociology Compass, 7(11), str. 965-983. DOI: 10.1111/soc4.12085

Burayidi, M. A. (2001): Introduction: Downtowns and small city development. V: Burayidi, M. A. (ur.): Downtowns: Revitalizing the centers of small urban communities, str. 1-6. New York, Routledge. DOI: $10.4324 / 9781315889436$

Burchell, R., Shad, N., Listokin, D., Phillips, H., Downs, A., Seskin, S., idr. (1998): The costs of sprawl - revisited. Transit cooperative research program report 39. Washington, National Academy Press.

Cameron, S. (1992): Housing, gentrification and urban regeneration policies. Urban Studies, 29(1), str. 3-14. DOI: 10.1080/00420989220080011

Carmon, N. (1999): Three generations of urban renewal policies: Analysis and policy implications. Geoforum, 30(2), str. 145-158.

DOI: 10.1016/s0016-7185(99)00012-3

Carmona, M. (2015): London's local high streets: The problems, potential and complexities of mixed street corridors. Progress in Planning, 100, str. 1-84. DOI: 10.1016/j.progress.2014.03.001

Cerreta, M., Daldanise, G., in Sposito, S. (2018): Culture-led regeneration for urban spaces: Monitoring complex values networks in action. Urbani izziv, 29(posebna izdaja), str. 9-28.

DOI: 10.5379/urbani-izziv-en-2018-29-supplement-001

Dawson, J. A. (1988): Futures for the high street. The Geographical Journal, 154(1), str. 1-12.

Degen, M. (2018): Timescapes of urban change: The temporalities of regenerated streets. The Sociological Review, 66(5), str. 1074-1092. DOI: $10.1177 / 0038026118771290$

Degen, M. (2004): The power of sensuous ideologies in framing the city. Prispevek je bil predstavljen na konferenci z naslovom 11th International Planning History Conference »Planning Models and the Culture of Cities«, ki je potekala od 14. do 17. julija v Barceloni v Španiji. Tipkopis. Dostopno na: https://www.academia.edu/17032481/The_power_of_sensuous_ideologies_in_framing_the_city (sneto 15. 2. 2020).

Dines, N. (2018): What's in a word? Contextual diversity, urban ethnography and the linguistic limits of the street. The Sociological Review, 66(5), str. 952-967. DOI: 10.1177/0038026118771289
El-Sayyad, N. (2019) Role of sensory maps in cultural planning to shape the future of deteriorated heritage sites. Prispevek je bil predstavljen na konferenci z naslovom 8th International Conference »ARCHCAIRO8«: Building the Future »Now» - Rights to Better Living, Architecture and Contexts, ki je potekala od 8. do 10. aprila v Kairu v Egiptu. Tipkopis. Dostopno na: http://www.academia.edu/download/59005500/ ROLE_OF_SENSORY_MAPS_IN_CULTURAL_PLANNING_TO_SHAPE_THE_ FUTURE_OF_DETERIORATED_HERITAGE_SITES20190423-122828-1kz2xcf. pdf (sneto 15. 2. 2020).

Filion, P., in Bunting, T. (2006): Understanding twenty-first century urban structure. V: Bunting, T., in Filion, P. (ur.): Canadian cities in transition, str. 1-23. Don Mills, Oxford University Press. DOI: $10.1080 / 00420989220081411$

Gawlik, K. (2012): Badania fokusowe. V: Jemielniak, D. (ur.): Badania jakościowe. Metody i narzędzia, str. 131-162. Varšava, Wydawnictwo Naukowe PWN.

Gehl, J. (2010): Cities for the people. Washington, Island Press.

Griffiths, S., Vaughan, L., Haklay, M., in Jones, C. E. (2008): The sustainable suburban high street: A review of themes and approaches. Geography Compass, 2(4), str. 1155-1188. DOI: $10.1111 /$ j.1749-8198.2008.00117.x

Hechesky, L. (2005): Return to main street: An assessment of the main street revitalization program. Magistrsko delo. Huntington, WV, The Graduate College of Marshall University.

Henshaw, V. (2013): Urban smellscapes: Understanding and designing city smell environments. New York, Routledge. DOI: 10.4324/9780203072776

Hubbard, P. (1996): Urban design and city regeneration: Social representations of entrepreneurial landscapes. Urban Studies, 33(8), str. 1441-1461. DOI: 10.1080/0042098966745

Hubbard, P., in Lyon, D. (2018): Introduction: Streetlife - the shifting sociologies of the street. The Sociological Review, 66(5), str. 937-951. DOI: $10.1177 / 0038026118771281$

Internet 1: https://www.mainstreet.org/ (sneto: 3. 2. 2020).

Internet 2: https://pl.wikipedia.org/wiki/Płock (sneto 3. 2. 2020).

Internet 3: https://pl.wikipedia.org/wiki/Ulica_Tumska_w_Płocku (sneto 3. 2. 2020).

Kaźmierczak, B., Nowak, M., Palicki, S., in Pazder, D. (2011): Oceny rewitalizacji. Studium zmian na poznańskiej Śródce. Poznan, Wydawnictwo Wydziału Nauk Społecznych UAM.

Lefebvre, H. (2003): The urban revolution. Minneapolis, University of Minnesota Press.

Löw, M. (2008): The constitution of space: The structuration of spaces through the simultaneity of effect and perception. European Journal of Social Theory, 11(1), str. 25-49. DOI: 10.1177/1368431007085286

Luma, E. (2009): Tumska - drugie „imię" naszego miasta. V: Rydzewska, B., Luma, E., in Kras, A. (ur.): Dwa wieki Tumskiej. Wczoraj, dziś, jutro, str. 59-68. Plock, Książnica Płocka.

Marciniak, J. (2012): Galerie wykończyły Tumska. Tygodnik Płocki. Dostopno na: https://tp.com.pl/artykul/galerie-wykonczyly-tumska/687915 (sneto 15. 9. 2019).

Miciukiewicz, K. (2008): Półwiejska Street in transition: Gentrification or revitalisation? V: Nowak, M., in Nowosielski, M. (ur.): Declining cities/ Developing cities: Polish and German perspectives, str. 113-128. Poznan, Instytut Zachodni. 
Neto, L., Pinto, N., in Burns, M. (2014): Evaluating the impacts of urban regeneration companies in Portugal: The case of Porto. Planning Practice \& Research, 29(5), str. 525-542. DOI: 10.1080/02697459.2014.973685

Nowosielski, M. (2012a): Between area-based initiatives and community-development programmes. The example of the Soziale Stadt Programme. Sociologija i Prostor 194(3), str. 309-325.

DOI: $10.5673 /$ sip.50.3.2

Nowosielski, M. (2012b): Challenging urban exclusion? Theory and practice. Polish Sociological Review, 179(3), str. 369-383.

Rodaway, P. (1994): Sensuous geographies: Body, sense, and place. London, Routledge.

Robertson, K. (2004): The main street approach to downtown development: An examination of the four-point program. Journal of the Architectural and Planning Research, 21(1), str. 55-73.

Robertson, K. A. (1995): Downtown redevelopment strategies in the United States: An end-of-the-century assessment. Journal of the American Planning Association, 61(4), str. 429-437. DOI: 10.1080/01944369508975655

Rydzewska, B. (2009): Dwa wieki Tumskiej. Szkic z dziejów zabudowy ulicy. V: Rydzewska, B., Luma, E. in Kras, A. (ur.): Dwa wieki Tumskiej. Wczoraj, dziś, jutro, str. 5-33. Plock, Książnica Płocka.

Rzegocińska-Tyżuk, B. (2008): Fenomen ulicy głównej jako „serca miasta" - wybrane przykłady. Czasopismo Techniczne, 4-A, str. 115-125.

Seidman, K. (2004): Inner-city commercial revitalization: A literature review (working paper). Boston, Massachusetts Institute of Technology.

Stern, M. J., in Seifert, S. C. (2007): Culture and urban revitalization: A harvest document: Culture and community revitalization: A collaboration. 7. Dostopno na: http://repository.upenn.edu/siap_revitalization/7 (sneto 12. 2. 2020).

Thibaud, J.-P. (2011): The three dynamics of urban ambiances. V: LaBelle, B., in Martinho, C. (ur.): Sites of sound: Of architecture and the ear, str. 43-53. Berlin, Errant Bodies Press.

Thibaud, J.-P. (2015): The backstage of urban ambiances: When atmospheres pervade everyday experience. Emotion, Space and Society, 15, str. 39-46. DOI: 10.1016/j.emospa.2014.07.001

Tybura, J. (2019): Czy lubi pan(i) Tumską? Dlaczego aż co 10. płocczanin bywa na niej nie częściej niż raz w roku? Gazeta Wyborcza - Płock, 8. 2. 2019. Dostopno na: http://plock.wyborcza.pl/plock/7,35681,24442425,czy-lubi-pan-i-tumska-dlaczego-az-co-10-plocczanin-bywa-na.html (sneto 15. 9. 2019).

Wankhede, K., in Wahurwagh, A. (2016): The sensory experience and perception of urban spaces. International Journal on Emerging Technologies, 7(1), str. 741-744.

Waskul, D. D., in Vannini, P. (2008): Smell, odour, and somatic work: sense-making and sensory management. Social Psychology Quarterly, 71(1), str. 53-71. DOI: 10.1177/019027250807100107

Woźniak, H. (2008): Ulica Tumska: najładniejsza i najstraszniejsza. Gazeta Wyborcza - Płock, 18. 9. 2008. Dostopno na: http://plock.wyborcza.pl/ plock/1,35681,5710056,Ulica_Tumska_najladniejsza_i_najstraszniejsza. html (sneto 15. 9. 2019). 